\title{
PACCHIONIAN-LIKE BODIES IN THE HUMAN CANAL OF SCHLEMM*
}

\author{
BY \\ EUGENE WOLFF \\ From the Institute of Ophthalmology, London
}

As long ago as 1876 Key and Retzius suggested that the canal of Schlemm $\vec{\circ}$ was like a dural venous sinus, and Rochon-Duvigneaud (1892) was insistent on this point. Also, Wegefarth (1914), in experiments on the cerebro-spinal fluid, which ran parallel with those of Weed (1914), showed that Pacchionian- $\frac{0}{0}$. like bodies occurred in Schlemm's canal in cats, dogs, rabbits, and monkeys. Since, however, this way of thinking is by no means universal, this article $\stackrel{i}{\sim}$ attempts to show that Pacchionian-like $\vec{\circ}$

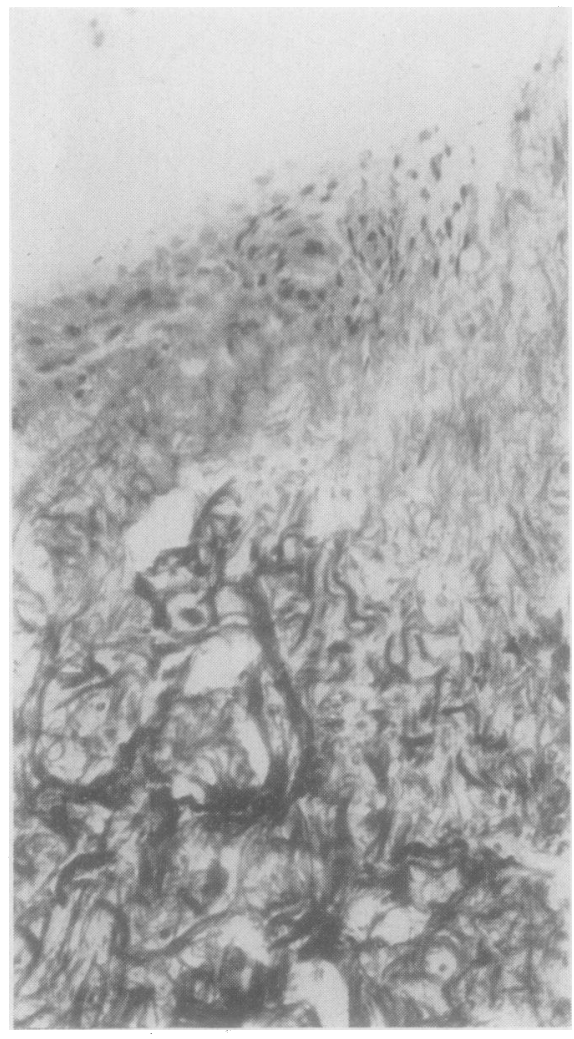

FIG. 1.-Section of Pacchionian body. Note two kinds of connective tissue. Zenker. Mallory's triple stain. $\times 184$. bodies occur normally in the canal of Schlemm in man.

Now haematoxylin and eosin, and van Gieson, are invaluable stains, but one may be led completely astray if one employs them for demonstrating ver $\overrightarrow{0}$ fine connective tissue fibrils. Thus the $\mathrm{N}$ vessels of the iris are classically deso cribed as having thick walls of almost hyaline appearance, whereas with Mallory's triple stain after Zenker fixation they are shown to consist in fact of extremely fine connective tissue fibrils.

For the same reason, I would suggest, a great deal of misconception still exists about the connective tissue content of $\dot{ }$ the Pacchionian bodies and the structure of the inner wall of the canal of Schlemm.

A Pacchionian body is formed, as Luschka (1852) showed, by the growth of a normally occurring arachnoidal $N$ villus through the dura into the over- $N$ lying venous sinus or lacuna lateralis. A Pacchionian body is thus at its commencement the same as villus, but $\varrho$

* Received for publication December 10, 1951. 
where macroscopic usually consists of several lobules and villi covered by a common endothelial membrane and possessing a common stalk. The Pacchionian body is usually covered by a layer of flattened cells containing large nuclei and lightly staining protoplasm (Le Gros Clark, 1920), but the endothelium may consist of two or many layers (Fig. 1). The connective tissue content of the Pacchionian body is variously described, but usually, I think, according to the appearance seen in sections stained with haematoxylin and eosin or van Gieson. With Mallory's triple stain the following picture appears: directly under the endothelium is a layer consisting of exceedingly fine fibrils while deeper are much coarser fibres which are also much more loosely packed (Fig. 1).

The relative size of the fibres of these two characteristic types of connective tissue may be judged from the fact that a $\frac{1}{6}$ objective is required for the fine ones, while the coarser ones are seen with a $\frac{2}{3}$ objective and even with a much lower power. The fine fibres are the continuation of the arachnoid, the coarser ones of the subarachnoid trabeculae.

The villi may be covered by a single layer of cells, but in some these form a multi-layered cap (Fig. 2); beneath the endothelium is the layer of fine

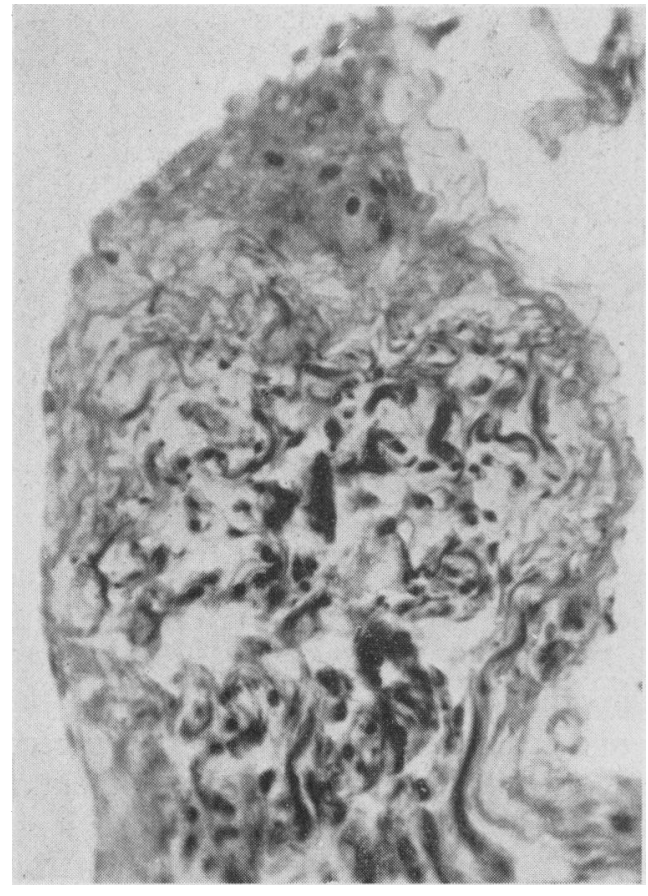

FIG. 2.-Arachnoidal villus. Note multi-layered nuclear cap, also fine fibrils below endothelium and coarse subarachnoid trabecula forming core. $\times 265$.

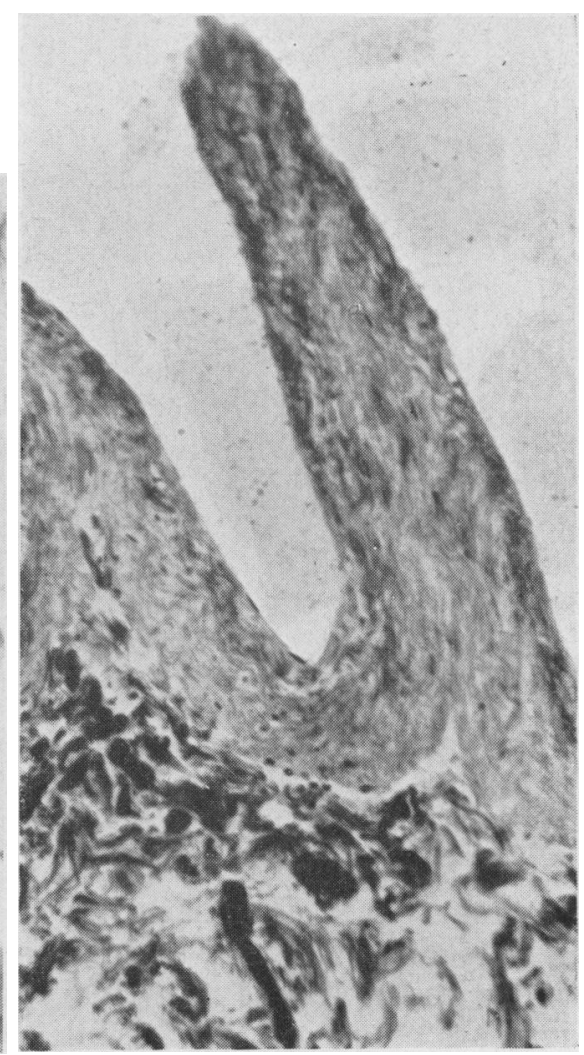

FIG. 3.-Arachnoidal villus. Note fine fibrils in projection and coarse fibrils at base. $\times 169$. 
fibrils, while the core is formed of the coarser subarachnoid trabeculae, or the whole villus may consist of the fine fibrils while the coarser ones run across the base (Fig. 3). There are, thus, two types of arachnoidal villi, a fact, incidentally, which I have not found mentioned in the literature.

The inner wall of the canal of Schlemm is usually flat but it may project into the lumen-like villus (Fig. 4), and may indeed reach the outer wall. It is usually lined by a single layer of cells, which are like those covering the $\frac{\bar{s}}{\bar{D}}$ Pacchionian body, but it may be in two or more layers, and may even form $\stackrel{\odot}{\circ}$ a multi-layered cap (Fig. 4).

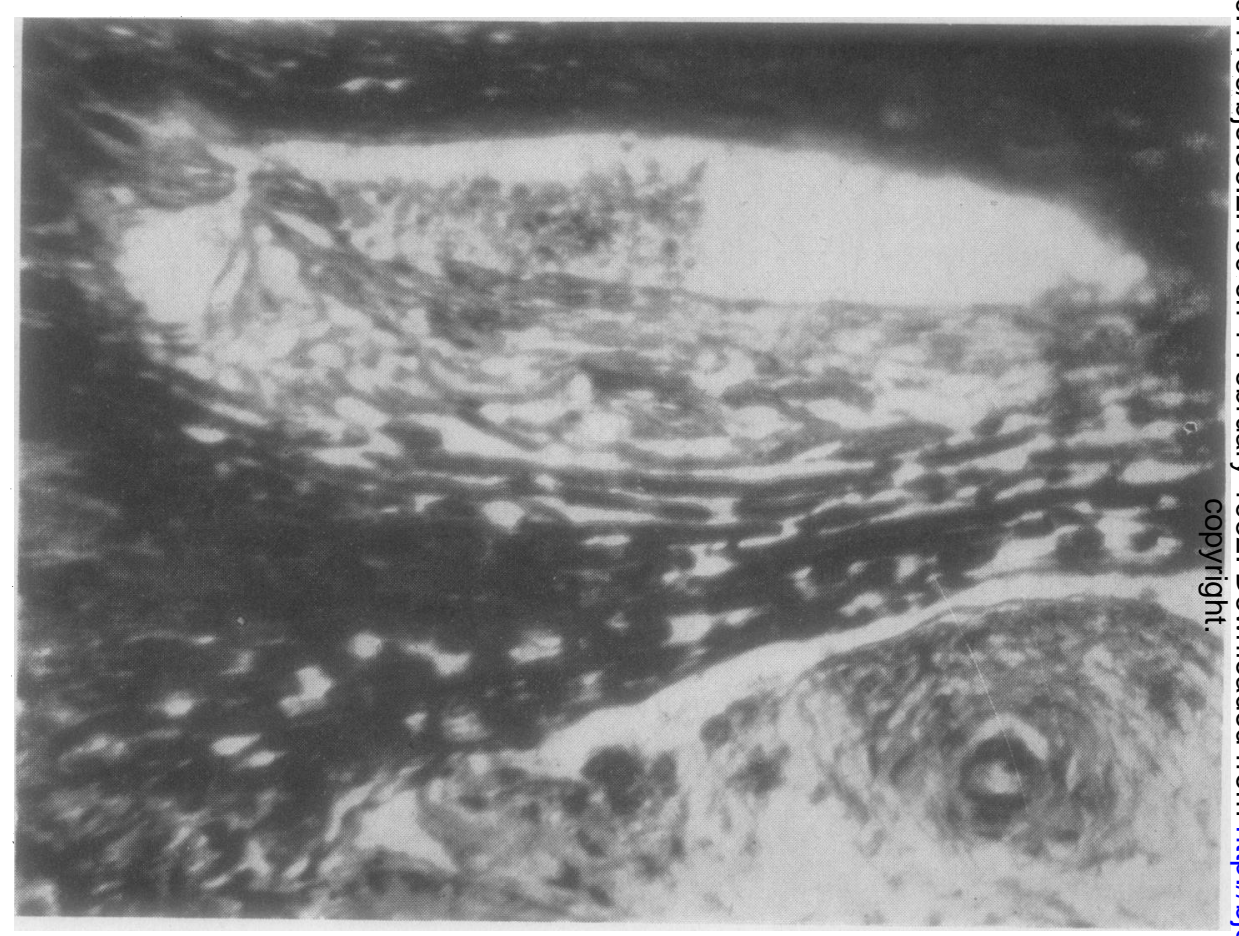

FIG. 4.-Section of canal of Schlemm. $\quad \times 230 . \quad$ Multinuclear cap in projection of inner wall, fine fibrils beneath endothelium. The canal contains blood.

Furthermore, this inner wall is usually described as being formed by the

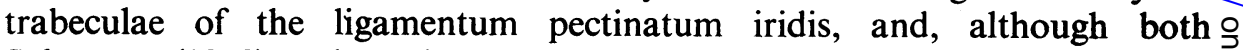
Salzmann (1912) and Rochon-Duvigneaud (1892) noted a different type of $D$ tissue directly under the endothelium, they were doubtless describing the appearance seen when haematoxylin and eosin or van Gieson had been used $N$ as the stain. Salzmann said the tissue resembles that under the endothelium $N$ of the outer wall of the canal, and Rochon-Duvigneaud described it as $\underset{\omega}{N}$ compact or dense. With Mallory's triple stain after Zenker fixation this tissue is seen to consist of a reticulum of very fine fibrils; it probably has the $\stackrel{0}{C}$ consistency of cotton wool, and I would suggest that it is homologous with $\stackrel{\oplus}{\oplus}$ 
the tissue under the endothelium of a Pacchionian body or arachnoidal villus, that is, with the protruded arachnoid.

Deep to this are some fibres which resemble those of the main mass of the ligamentum, but are frailer and contain only an ill-defined core of connective and elastic tissue; these no doubt represent the subarachnoid trabeculae.

The trabeculae of the ligamentum, with their well-marked core of connective and elastic tissue, follow; they have the characteristics of scleral tissue and doubtless represent the dura through which the villus makes its way.

Thus there can be little doubt that Pacchionian-like bodies occur in the human canal of Schlemm.

\section{SUMMARY}

With Mallory's triple stain following Zenker fixation the structure of the inner wall of the canal of Schlemm in man is as follows:

The inner wall may be flat or jut in like a villus. It may even reach the outer wall. It is usually lined by a single layer of endothelium, but this may be in two or more layers and may even form a cap of nuclei like that in a Pacchionian body or arachnoidal villus. Beneath this is a layer of very fine fibrils like those beneath the endothelium of a Pacchionian body. Deep to this are trabeculae which resemble the subarachnoid trabeculae of a Pacchionian body. Then and then only come the trabeculae of the ligamentum pectinatum iridis.

My thanks are due to Dr. Peter Hansell and the medical illustration department at the Institute of Ophthalmology for the photographs.

\section{REFERENCES}

Clark, W. E. Le Gros (1920). J. Anat., Lond., 55, 40.

KeY, A., and Retzius, G. (1876). "Studien in der Anatomie des Nervensystems und des Bindegewebes". Samson and Wallin, Stockholm. Quoted by Wegefarth (1914).

LuschKa, (1852). Arch. Anat. Physiol. Lpz., p. 101.

ROCHON-DUvigNEAUD, (1892). "Recherches sur l'angle de la chambre antérieure et le canal de Schlemm ". Steinheil, Paris. Thèse de Paris, No. 223.

SalzmanN, M. (1912). " Anatomy and Histology of the Human Eyeball in the Normal State", trans. E. V. L. Brown. Univ. Chicago Press.

WEED, L. H. (1914). J. med. Res., 31, 21.

WEGEFARTH, P. (1914). Ibid., 31, 119. 